\title{
HEAT TRANSFER COEFFICIENTS IN CONCENTRIC ANNULI
}

\author{
J Dirker * and J.P Meyer** \\ "M.Eng. Student; ** Professor \\ Department Mechanical and Manufacturing Engineering, \\ Rand Afrikaans University, \\ P.O. Box 524, Auckland Park, 2006, \\ South Africa \\ E-mail: jpm@ing.rau.ac.za
}

\begin{abstract}
The geometric shape of a passage's cross-section has an effect on its convective heat transfer capabilities. For concentric annuli, as cross section, the diameter ratio of the annular space plays an important role. The purpose of this investigation was to find a correlation that will accurately predict heat transfer coefficients at the inner wall of smooth concentric annuli for the flow of water. Experiments were conducted on water under turbulent flow conditions for a wide range of diameter ratios. The Wilson plot method was used to determine the heat transfer coefficients from which a correlation was developed that could be used to predict the heat transfer coefficients.

It was found that the correlation predicted Nusselt numbers accurately within $3 \%$ of measured values for diameter ratios between $a=1.7$ and $a=5.1$ and a Reynolds numbers range of 4000 to 30000 .
\end{abstract}

\section{INTRODUCTION}

Since the early nineteen hundreds, many researchers have investigated heat transfer in annuli, particularly in order to find correlations that can describe the Nusselt number $(\mathrm{Nu})$ and convective heat transfer for a wide range of flow conditions and annular diameter ratios. Figure 1 shows a schematic representation of a basic tube-in-tube element. Most of the proposed equations for calculating the Nusselt number are functions of the annular diameter ratio $\left(a=D_{2} / D_{l}\right)$, the Reynolds number $(\mathrm{Re})$ and the Prandtl $(\mathrm{Pr})$ number and corresponds with the Dittus-Boelter type form.

Figure 2 indicates a comparison of Nusselt number predictions of some of the equations sited in literature with an annular ratio of 2 and a Prandtl number of 3.36

All correlations predict an almost linear increase in the Nusselt number with an increase in the Reynolds number. Compared to the other predictions, the equation by Foust and Christian over predicts the Nusselt number by approximately a factor of three. When the predictions of Foust and Christian are omitted, a difference in predicted values of $-20 \%$ to $+25 \%$ relative to the average predicted value is found to exist.

No literature was found that indicates the existence of an accurate heat transfer correlation for concentric annuli. It was thus the purpose of this investigation to deduce a correlation that would be able to make accurate predictions of average Nusselt numbers at the inner annular wall under turbulent flow conditions of water.

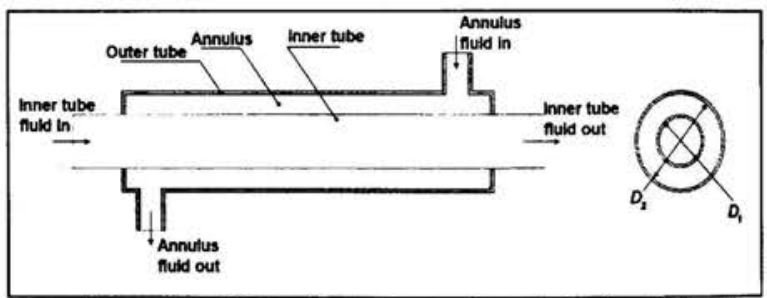

Figure 1: Schematic representation of a basic tube-intube heat exchanger element.

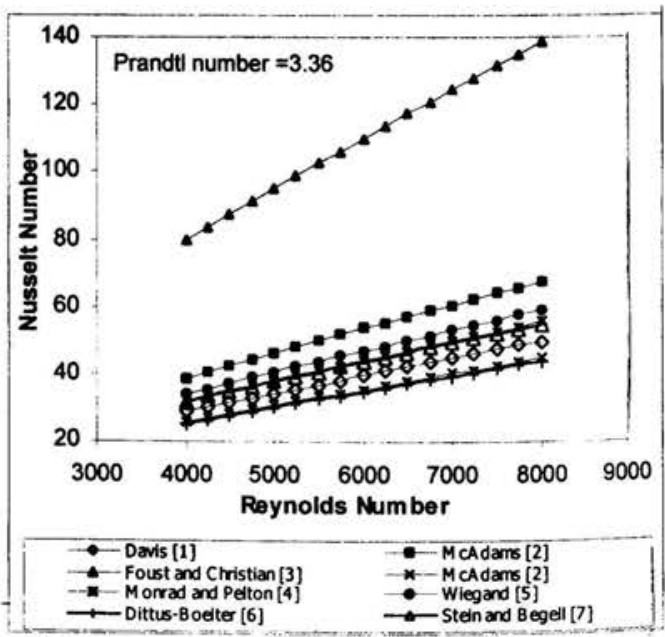

Figure 2: The predictions of the Nusselt number as a function of the Reynolds number for $a=2$.

\section{NOMENCLATURE}

a annular diameter ratio $\left[\mathrm{D}_{2} / \mathrm{D}_{1}\right]$

$c_{p} \quad$ specific heat $(\mathrm{J} / \mathrm{kgK})$ 
$C_{i} \quad$ inner tube convective heat transfer correlation coefficient - Wilson plot

$C_{o}$ annulus convective heat transfer correlation coefficient - Wilson plot

$D_{1}$ diameter of outer wall of inner tube (m)

$D_{2} \quad$ diameter of inner wall of outer tube (m)

$D_{h} \quad$ hydraulic diameter of annulus $(\mathrm{m})\left[D_{2}-D_{l}\right]$

$D_{i} \quad$ inner diameter of inner tube $(\mathrm{m})$

$h$ convective heat transfer coefficient $\left(\mathrm{W} / \mathrm{m}^{2} \mathrm{~K}\right)$

$k$ thermal conductivity $(\mathrm{W} / \mathrm{mK})$

$L \quad$ length of heat exchanger (m)

$\mathrm{Nu}_{i}$ inner tube Nusselt number $\left[h_{i} D / k_{i}\right]$

$\mathrm{Nu}_{o}$ annular Nusselt number $\left[h_{o} D_{h} / k_{o}\right]$

$P \quad$ exponent of Reynolds number in Wilson plot function

Pr Prandtl number $\left[c_{p} \mu / k\right]$

$\mathrm{Re}_{i} \quad$ inner tube Reynolds number $\left[\rho_{i} u_{i} D_{i} / \mu_{i}\right]$

$\operatorname{Re}_{o} \quad$ annular Reynolds number $\quad\left[\rho_{o} u_{o} D_{h} / \mu_{o}\right]$

$U$ overall heat transfer coefficient $\left(\mathrm{W} / \mathrm{m}^{2} \mathrm{~K}\right)$

$u \quad$ axial velocity $(\mathrm{m} / \mathrm{s})$

\section{Greek symbols}

$\gamma \quad$ corrective function

$\mu \quad$ viscosity $\left(\mathrm{Ns} / \mathrm{m}^{2}\right)$

$\rho$ density $\left(\mathrm{kg} / \mathrm{m}^{3}\right)$

\section{Subscripts}

$D_{h} \quad$ based on the hydraulic diameter of the annulus

$i$ inner tube side

$o \quad$ annulus side

w wall

\section{EXPERIMENTAL FACILITY}

Eight different concentric tube-in-tube heat exchangers, each with a different annular diameter ratio, were used during the experimental investigation. Each heat exchanger had an effective heat transfer length of about $6 \mathrm{~m}$ and was operated in a counter flow arrangement with hot water in the inner tube and cold water in the annulus. The heat exchangers were constructed from hard drawn refrigeration copper tubing and were operated in a horizontal configuration. Dimensions of the different heat exchangers are listed in Table 1.

Table 1 Physical dimensions of horizontal counter flow heat exchangers used during experimental investigations.

\begin{tabular}{lrrrrr}
\hline $\begin{array}{l}\text { Heat } \\
\text { Exchanger }\end{array}$ & $\begin{array}{r}D_{i} \\
{[\mathrm{~mm}]}\end{array}$ & $\begin{array}{r}D_{1} \\
{[\mathrm{~mm}]}\end{array}$ & $\begin{array}{r}D_{2} \\
{[\mathrm{~mm}]}\end{array}$ & $a$ & $L$ \\
\hline 1 & 5.30 & 6.35 & 11.15 & 1.76 & 6.170 \\
2 & 5.30 & 6.35 & 14.10 & 2.22 & 6.095 \\
3 & 5.30 & 6.35 & 17.30 & 2.72 & 6.160 \\
4 & 5.30 & 6.35 & 20.30 & 3.20 & 6.170 \\
5 & 5.30 & 6.35 & 26.50 & 4.17 & 6.200 \\
6 & 5.30 & 6.35 & 32.00 & 5.04 & 6.240 \\
7 & 8.00 & 9.45 & 32.00 & 3.39 & 6.260 \\
8 & 17.30 & 19.05 & 32.00 & 1.68 & 6.200 \\
\hline
\end{tabular}

The inner tubes were kept in concentric positions by employing sets of either three or four radial supporting metal pins along the length of each heat exchanger. The pins had a diameter of
$0.6 \mathrm{~mm}$ and were at an offset of either $90^{\circ}$ or $120^{\circ}$ while clamping the inner tube. The pins were only fixed to the outer tube to minimise the effect of possible thermal conduction from the hot inner tube to the metal pins, which might have acted as fins. A representation of one set of four supporting pins with an offset of $90^{\circ}$ is shown in Figure 3.

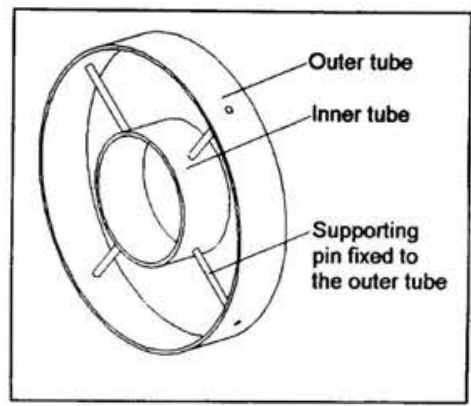

Figure 3: A representation of one set of supporting pins with an offset of $90^{\circ}$.

By using a symmetrical configuration, possible unbalanced flow patterns were minimised. Supporting sets were placed at distances of between $0.75 \mathrm{~m}$ and $0.667 \mathrm{~m}$ apart along the length of each heat exchanger depending on the cross sectional area of the annulus. The size and position of the supporting pins were carefully chosen to minimise possible turbulence generation. The supporting structures occupied at most $6.5 \%$ of the cross sectional area of the smallest annulus.

Temperature measurements were facilitated by means of K-type thermocouples fixed on the outside surfaces at entry and exit regions of the heat exchangers. Temperature data was captured with the aid of a data logger. Temperature errors were usually less than $0.1^{\circ} \mathrm{C}$. Measuring points were sufficiently insulated from the ambient.

Volumetric flow rates were measured by using semi-rotary circular-piston-type displacement flow meters with a measuring accuracy of greater than $98 \%$. The flow meters were installed at the exits of both the hot and cold-water tubes of the heat exchangers. By allowing a distance of at least $1 \mathrm{~m}$ from the outlets, the chaotic flow patterns generated at the exit regions were decreased before entering the flow meters. This ensured more accurate flow rate measurement. The flow meters were installed at the exit regions as the high pressures at the inlet regions might influence the operation of the flow meters negatively.

Hot-water supplied by an on-site hot-water storage tank $(1000 l)$, fitted with an electric resistance water heater, was pumped through the inner tube by means of a positive displacement pump and then returned to the storage tank. The hot-water flow rates were controlled with hand-operated valves. By directing an amount of the flow through a bypass, the pressures inside the heat exchangers were reduced.

Similarly, cold water was supplied from a cold water storage tank $(1000 l)$ connected to a chiller and pumped 
More than $95 \%$ of all data points were predicted within a $3 \%$ accuracy range by the Wilson plot correlations for the different heat exchangers. All Wilson plot correlations exhibited a median error of less than or in close proximity to $1 \%$. Standard deviances for error values were less than $2 \%$.

The correlation for heat exchanger 7 had less than desired accuracies due to inconsistency in the Wilson plot results. It may be likely due to a physical defect in the annulus.

Table 3: Annular Wilson plot correlation results obtained for the eight heat exchangers.

\begin{tabular}{|c|c|c|c|c|c|}
\hline \multirow[b]{2}{*}{$\begin{array}{c}\text { Heat } \\
\text { Exchanger }\end{array}$} & \multirow[b]{2}{*}{$a$} & \multicolumn{2}{|c|}{ Wilson Plot Variables } & \multicolumn{2}{|c|}{$U_{o}$ Prediction Error } \\
\hline & & $P$ & $C_{o}$ & Median & $\begin{array}{l}\text { Standard } \\
\text { Deviation }\end{array}$ \\
\hline & {$[-]$} & {$[-]$} & {$[-]$} & {$[\%]$} & {$[\%]$} \\
\hline 1 & 1.76 & 0.8973 & 0.0085 & 0.895 & 1.188 \\
\hline 2 & 2.22 & 0.8319 & 0.0171 & 0.991 & 1.429 \\
\hline 3 & 2.68 & 0.8533 & 0.0152 & 0.775 & 1.059 \\
\hline 4 & 3.2 & 0.8351 & 0.0194 & 1.028 & 1.920 \\
\hline 5 & 4.17 & 0.6223 & 0.1415 & 0.526 & 1.044 \\
\hline 6 & 5.04 & 0.7175 & 0.0637 & 0.158 & 1.447 \\
\hline 7 & 3.39 & 1.0787 & 0.0018 & 0.163 & 1.257 \\
\hline 8 & 1.68 & 0.9256 & 0.0068 & 0.305 & 1.116 \\
\hline
\end{tabular}

\section{DERIVATION OF CORRELATION}

As was expected both $P$ and $C_{o}$ (equation 2) showed a dependence on the annular diameter ratio. Figure 5 illustrates the general trends of $P$ and $C_{o}$ in terms of the diameter ratio. The value of $P$ exhibited a downward trend as the annular diameter ratio is increased. On the other hand, the value of $C_{o}$ had an upward trend for an increasing annular diameter ratio.

The results obtained from data of heat exchangers 5 and 7 do not agree with those of the rest of the heat exchangers. (annular diameter ratios of 4.17 and 3.39 respectively) This is highlighted in Figure 5.

It is suspected that the heat exchangers suffered internal mechanical damage. A strong possibility exists that the inner tubes were not concentrically spaced inside the annulus. It is known from literature that the presence of eccentricity has an effect on heat transfer correlations as was found by Coldwell [9] as well as Lea and Taros [10]. It was decided to exclude results obtained from heat exchanger 5 and 7 from the derivation process, as it would have impacted negatively on the accuracy of the final generalised correlation, in the worst case nullifying the good results obtained from the other six heat exchangers.

The first step was to find general mathematical relations could predict the values of $P$ and $C_{o}$ of the remaining annular cases in terms of the diameter ratio, $a$. Figures 6 and 7 show how relations (3) and (4) approximate the Wilson plot variables of $P$ and $C_{o}$ respectively. The coefficients of determination $\left(R^{2}\right)$ are also included.

$$
\begin{aligned}
& P=1.013 e^{-0.067 a} \\
& \left(R^{2}=0.9020\right) \\
& C_{o}=0.003 a^{1.86} \\
& \left(R^{2}=0.9613\right)
\end{aligned}
$$

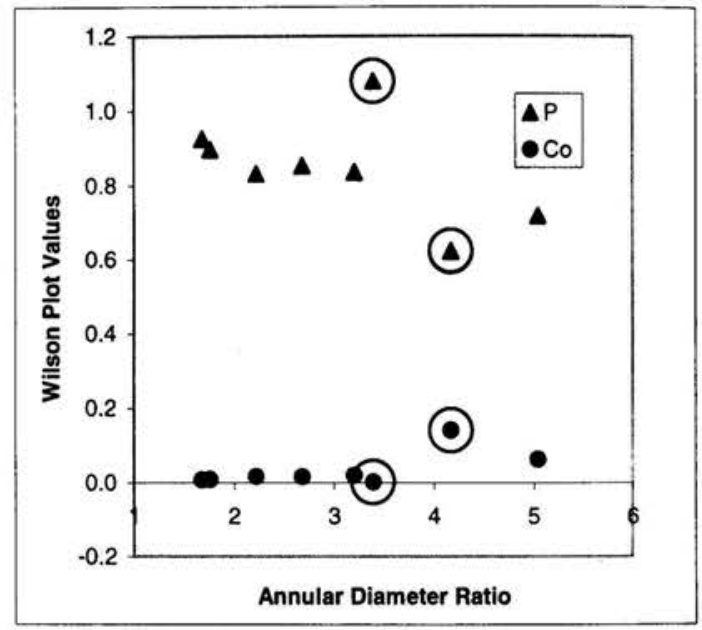

Figure 5: Combined representation of Wilson plot result with suspicious results of heat exchangers 5 and 7 encircled.

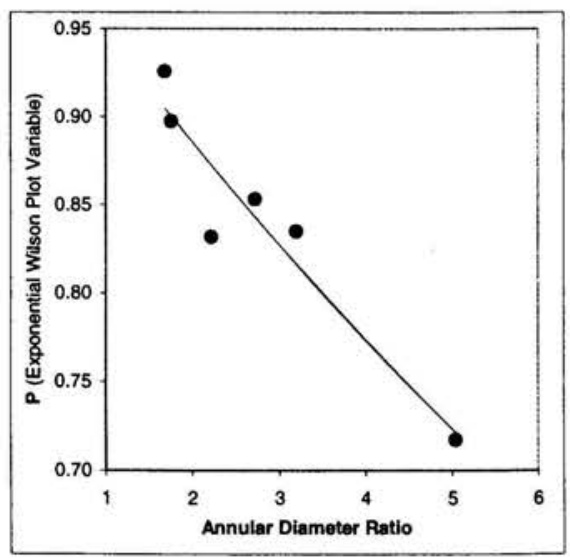

Figure 6: Exponential function approximation used for the value of $P$ in terms of the annular diameter ratio. (equation 23) 
through the annulus by means of two series connected centrifugal pumps to ensure high flow rates before being returned to the storage tank. The cold water flow rates were also controlled by means of a bypass system and hand-operated valves. A schematic representation of the test facility is shown in Figure 4.

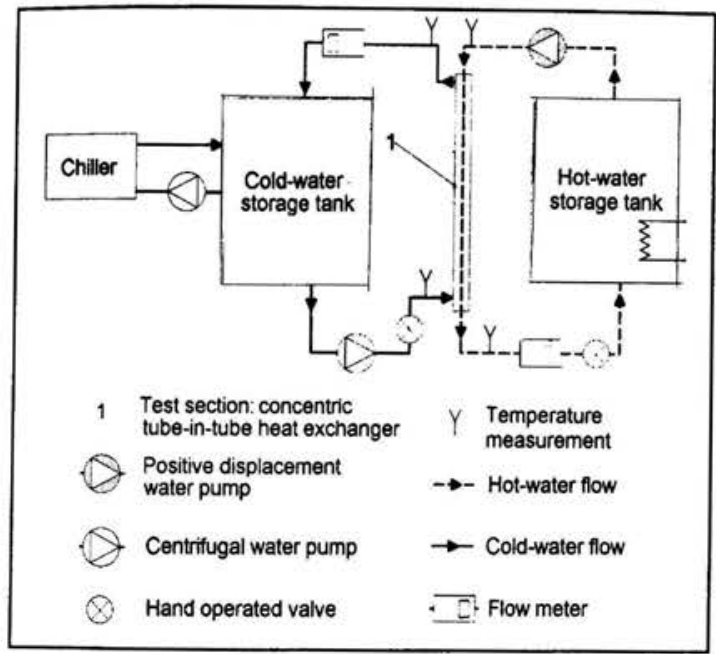

Figure 4: Schematic representation of experimental facility.

\section{EXPERIMENTAL PROCEDURE}

Experimental tests were performed at a wide range of flow rate combinations between the inner tube and annulus. As a correlation for the annulus was being deduced, the flow rates in the annulus were of more importance and a bigger spectrum was covered, ensuring a turbulent flow regime. By adjusting the hand-operated valves the appropriate flow rates could be established.

Experiments were started with the inner tube flow rate constant for a number of tests while the annular flow rate was altered through the spectrum. Thereafter a new inner tube flow rate was used and the procedure repeated. After sufficient time was allowed for relative steady state conditions to be established, inlet and outlet temperatures of the inner tube and annulus were recorded by means of the data logger.

Before moving on to a next test, it was insured that the energy balance error was at a satisfactory low level. If the error was too high, a longer time period was given for the system to reach an approximate steady state. A high level of accuracy in the experimental data was maintained. More than $90 \%$ of all data points exhibited an energy balance error of less than $1 \%$. A Reynolds number range of 2600 to 35000 was covered in experiments performed on eight heat exchangers. Suspicious data points were excluded from the analysis process to increase the final accuracy thereof. Information on the experimental data and data sets used for analysis purposes is given in Table 2 .

In the case of heat exchanger 7 , experiemental tests were repeated due to discrepancies in results obtained from its data.

\section{PROCESSING OF DATA}

The internal and annular Nusselt numbers can be written as follows:

$$
\begin{aligned}
& N u_{i}=\frac{h_{i} D_{i}}{k_{i}}=C_{i} \operatorname{Re}_{i}^{0.8} \operatorname{Pr}_{i}^{\frac{1}{3}}\left(\frac{\mu}{\mu_{w}}\right)_{i}^{0.14} \\
& N u_{o}=\frac{h_{o} D_{h}}{k_{o}}=C_{o} \operatorname{Re}_{o}^{P} \operatorname{Pr}_{o}^{\frac{1}{3}}\left(\frac{\mu}{\mu_{w}}\right)_{o}^{0.14}
\end{aligned}
$$

Factors $P, C_{i}$ and $C_{o}$ are added to account for geometry influences. The modified Wilson plot method developed by Briggs and Young [8] was used to determine these values for the different annular diameter ratios.

Obtained values are listed in Table 3 accompanied by information on the error of the resulting correlations (equation 2 ) on the data in terms of the annular overall heat transfer coefficient $U_{o}$.

\begin{tabular}{|c|c|c|c|c|c|c|c|}
\hline \multirow{2}{*}{$\begin{array}{c}\text { Heat } \\
\text { Exchanger } \\
-\end{array}$} & \multirow{2}{*}{$a$} & \multirow{2}{*}{$\begin{array}{c}\text { Number of Tests } \\
\text { Performed }\end{array}$} & \multirow{2}{*}{$\begin{array}{l}\text { Number of Data Points } \\
\text { Used for Analyses } \\
\end{array}$} & \multicolumn{2}{|c|}{$\operatorname{Re}_{D_{h}}$} & \multicolumn{2}{|c|}{ Energy Balance Errors } \\
\hline & & & & $\begin{array}{c}\text { Minimum } \\
{[-]}\end{array}$ & $\begin{array}{c}\text { Maximum } \\
{[-]}\end{array}$ & $\begin{array}{c}\text { Median } \\
{[\%]}\end{array}$ & $\begin{array}{c}\text { Standard Deviance } \\
{[\%]}\end{array}$ \\
\hline 1 & 1.76 & 50 & 50 & 8065 & 24117 & 0.731 & 0.330 \\
\hline 2 & 2.22 & 50 & 50 & 6422 & 31484 & 0.049 & 0.407 \\
\hline 3 & 2.68 & 30 & 30 & 6066 & 34887 & 0.029 & 0.613 \\
\hline 4 & 3.2 & 50 & 50 & 4562 & 28093 & 0.612 & 0.473 \\
\hline 5 & 4.17 & 50 & 50 & 3823 & 17238 & 0.603 & 0.554 \\
\hline 6 & 5.04 & 30 & 21 & 3457 & 18538 & 0.463 & 0.558 \\
\hline $7^{\circ}$ & 3.39 & 21 & - & 3553 & 16665 & 0.686 & 0.756 \\
\hline & & 30 & 18 & 3553 & 16665 & 0.210 & 0.689 \\
\hline 8 & 1.68 & 50 & 50 & 2631 & 14425 & 1.159 & 0.739 \\
\hline
\end{tabular}

Table 2: Information on Experimental data sets and energy balance errors. 


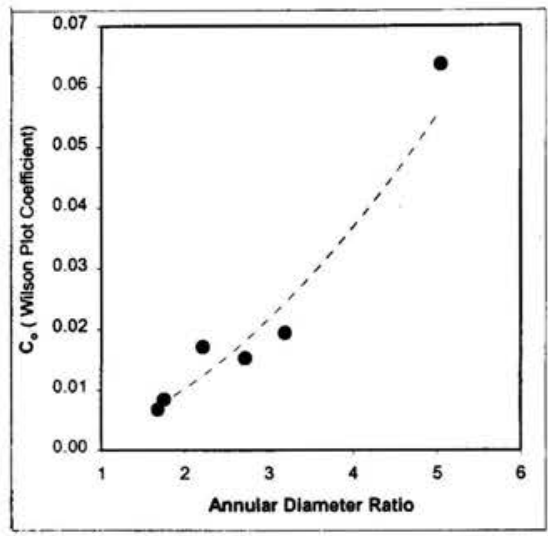

Figure 7: Power function approximation used for the value of $C_{0}$ in terms of the annular diameter ratio. (equation 24)

Furthermore it was found that the following relation also exists between $P, C_{o}$ and $a$ :

$\frac{P C_{o}^{0.161}}{a^{0.949}}=0.3961$

$\left(R^{2}=0.9796\right)$

This is demonstrated by Figure 8 .

By using equations (2) in conjunction with equations (3) and (4) the expected values for the annular Nusselt number can be determined for a particular temperature, Reynolds number and diameter ratio. The percentage deviances of the predicted Nusselt numbers were determined for a range in Reynolds number of 4000 to 30000 . The median values of these are given in Table 4.

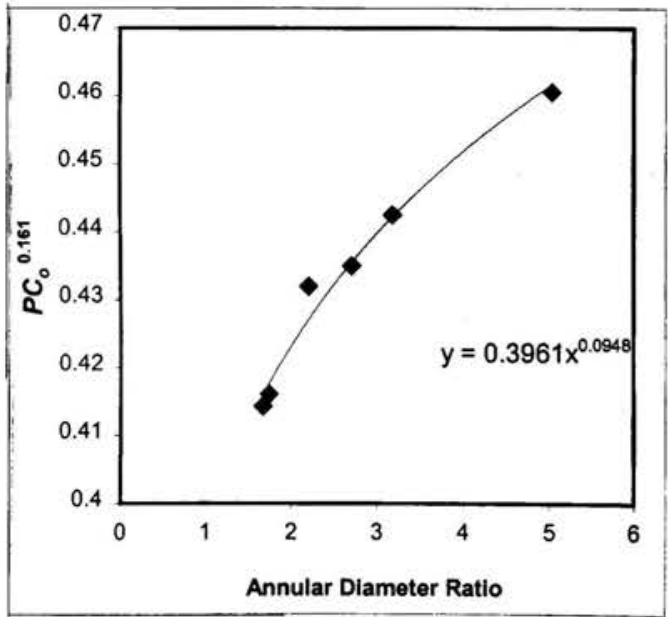

Figure 8: Relation shown between $P, C_{o}$ and the annular diameter ratio, $a$.
Table 4: Expected percentage deviances for the different diameter cases using initial correlations for $P$ and $C_{o}$ (equations 23 and 24) for a Reynolds number range of 4000 to 30000 .

\begin{tabular}{ccc} 
Heat Exchanger & $a$ & $\begin{array}{c}\text { Median Percentage Deviance } \\
{[\%]}\end{array}$ \\
1 & {$[-]$} & 4.3 \\
2 & 1.76 & 15.6 \\
3 & 2.22 & 16.0 \\
4 & 2.72 & 13.6 \\
6 & 3.20 & 0.4 \\
8 & 5.04 & -5.0 \\
\hline
\end{tabular}

From the information listed in Table 4 , the initial correlations for $P$ and $C_{o}$, it was expected that predictions of the Nusselt numbers would be too great. More accurate correlations were thus required to describe the Nusselt number in terms of the annular diameter ratio.

By dividing the initial correlation for the Nusselt number by a corrective function defined by equation (6), this problem was solved and the resulting deviances were within a $3 \%$ range. The median values for the different diameter ratios are given in Table 5 .

$\gamma=0.063 a^{3}-0.674 a^{2}+2.225 a-1.157$

After substituting correlations for $P$ and $C_{o}$ into equation (2), and including the corrective function, the resulting Nusseit number correlation is described by (7):

$N u_{o, D_{h}}=\frac{0.003 a^{1.86}}{\gamma} \operatorname{Re}_{o, D_{k}}^{1.013 e^{-0.0670}} \operatorname{Pr}_{o}^{\frac{1}{3}}\left(\frac{\mu}{\mu_{w}}\right)_{0}^{0.14}$

Table 5: Expected percentage deviances of the predicted Nusselt numbers after corrective function was included in correlations for $P$ and $C_{o}$ for a Reynolds number range of 4000 to 30000 .

Heat Exchanger $a$ Median Percentage Deviance

$\begin{array}{ccc} & {[-]} & {[\%]} \\ 1 & 1.76 & 2.9 \\ 2 & 2.22 & 0.2 \\ 3 & 2.72 & -1.3 \\ 4 & 3.20 & 0.9 \\ 6 & 5.04 & -0.1 \\ 8 & 1.68 & -2.6\end{array}$

\section{ACCURACIES}

The validity of equation (7) for the prediction of Nusselt numbers were tested with experimental data from all heat exchangers excluding heat exchangers 5 and 7 . These were excluded, as the data obtained from them would not suit the 
particular heat transfer conditions for this investigation namely turbulent flow in smooth concentric annuli.

Information on the resulting prediction errors is given in Table 6.

Table 6: Information on percentage errors experienced with each data set used for the correlation verification.

\begin{tabular}{lcccccc}
\hline $\begin{array}{l}\text { Data Set } \\
\text { (heat exchanger) }\end{array}$ & 1 & 2 & 3 & 4 & 6 & 8 \\
\hline Median & 2.146 & 0.431 & -1.692 & 0.686 & -0.440 & -1.448 \\
Standard Deviation & 0.515 & 1.809 & 0.473 & 0.928 & 0.186 & 1.022 \\
Maximum & 3.044 & 2.695 & -0.697 & 2.817 & -0.183 & 0.759 \\
Minimum & 1.174 & -3.948 & -2.258 & -0.522 & -0.980 & -2.635 \\
\hline
\end{tabular}

It was found that the presence of the corrective function has improved the accuracy of the correlation to within $3 \%$, with only a few minor extreme cases falling just outside it.

\section{CONCLUSION}

As was expected, it was found that the convective heat transfer correlation for an annulus is dependent on the diameter ratio. The value of $P$ (equation 2 ) exhibited a downward trend with an increase in the diameter ratio while the opposite was found to be true for the value of $C_{o}$ (equation 2).

It was found that the correlation deduced (equations 6 and 7) predicted Nusselt numbers accurately within $3 \%$ from the measured values for diameter ratios between $a=1.7$ and $a=5.1$ and a Reynolds numbers range of 4000 to 30000 .

It is recommended that the annular diameter ratio of heat exchangers 5 and 7, $a=4.17$ and $a=3.39$ respectably be reinvestigated in future as it would supply valuable additional information on the behavior of $P$ and $C_{o}$. More annular diameter ratio could also be included to establish a stronger heat transfer correlation.

\section{REFERENCES}

[1] Davis ES, Heat transfer and pressure drop in annuli, Transactions of ASME, (1943), Oct, p 755-760

[2] McAdams WH, Heat Transmissions $3^{\text {td }}$ ed., (1954), p 241-244

[3] Foust AS, Christian GA, Non-Boiling heat transfer coefficients in annuli, American Institute of Chemical Engineers, (1940), 36, p 541-554

[4] Monrad CC, Pelton JF, Heat transfer by convection in annular spaces, American Institute of Chemical Engineers, (1942), 38, p 593-611

[5] Wiegand JH, McMillen EL, Larson RE, Discussion on: Annular heat transfer coefficients for turbulent flow., American Institute of Chemical Engineers, (1945), 41, p 147-153

[6] Dittus FW, Boelter LMK, University of California, Berkeley, Publications on Engineering, (1930), 2, p 443

[7] Stein RP, Begell W, Heat transfer to water in turbulent flow in internally heated annuli. American Institute of Chemical Engineers Journal (1958) 4(2), June p 127 131

[8] Briggs DE, Young EH, Modified Wilson Plot Technique for obtaining Heat Transfer Correlations for Shell and Tube Heat Exchangers, Chemical Engineering Progress Symposium, (1969), 65, p 35-45

[9] Caldwell J, J. Roy. Tech. Coll. (Glasgow), (1930), 2, p 203

[10] Lea FC, Tadros AG, Phil. Mag., (1931), 11, p 1235 